\section{Ensuring accelerated accessibility and affordability of treatment services for COVID-19 patients in Zimbabwe: An urgent call to action}

To the Editor: Timely access to quality healthcare services is a basic human right. Governments globally have a responsibility to ensure wider coverage and access, particularly to essential and lifesaving healthcare services. For these reasons, there has been a strong call for universal health coverage. Private medical insurance promotes inequalities in accessing care, perpetuated by ever-widening socioeconomic gaps. In resource-constrained settings, the lower and more vulnerable social classes suffer more from disparities during crisis times such as the COVID-19 pandemic.

Zimbabwe, a country characterised by underinvestment in the public sector and unfavourable conditions for the healthcare workforce, has seen massive outward migration of health service providers to countries such as the UK, Australia, New Zealand, Canada and the USA. ${ }^{[1]}$ As a result, Zimbabwe has been ill-prepared to protect its population from the negative impact of COVID-19. Additionally, the sustained depreciation of the local currency has made conditions untenable for many health workers in the COVID19 era, where there are increased demands on their jobs. The prevailing hyperinflationary environment has led to the deterioration of equipment and frequent stock outages of essential commodities and consumables in the public sector, making it difficult, and sometimes impossible, for patients to access COVID-19 treatment and care services. Lack of consumables such as personal protective equipment (PPE) has worsened the situation, ${ }^{[2]}$ with PPE only being obtained earlier in the pandemic when health workers took the government to court to compel it to provide this essential equipment.

As patients struggle to access treatment services provided by the public sector, they have turned to the private sector, either to use established facilities or for home-based healthcare services. Reports have emerged of exorbitant upfront admission charges for COVID-19 patients, well beyond the reach of the majority, with essential medication also being sold at extortionate prices. For instance, there are reports that the scarce tocilizumab, a drug that has been widely prescribed for COVID-19, is being sold for over USD1 500 per dose, way above its cost on the market. ${ }^{[3]}$ There have been widespread unproven reports of COVID-19 treatment and prevention kits, containing medicines such as ivermectin, doxycycline and azithromycin, being sold for exorbitant prices. ${ }^{[4]}$
There is an urgent need for the government to provide a safety net for the suffering patients, protecting them from over-profiteering in the private sector. More importantly, the government must recognise its role as being central in the provision of quality and accessible healthcare to the people. We therefore call upon the government to prioritise building healthcare capacity and a robust and resilient system ahead of other priorities, as we prepare for inevitable further COVID-19 waves. We also implore the government to urgently address healthcare workers' genuine grievances, including demands for fair remuneration, health and life insurance, and provision of safe and adequate PPE.

Disclaimer. The views presented in this letter are those of the authors and do not necessarily represent the position of their institutions.

\section{Grant Murewanhema}

Unit of Obstetrics and Gynaecology, Department of Primary Health Care Sciences, Faculty of Medicine and Health Sciences, University of Zimbabwe, Harare, Zimbabwe

\section{Tafadzwa Dzinamarira}

School of Health Systems and Public Health, Faculty of Health

Sciences, University of Pretoria, South Africa

anthonydzina@gmail.com

\section{Helena Herrera}

University of Portsmouth, UK

\section{Godfrey Musuka}

ICAP at Columbia University, Harare, Zimbabwe

1. Dzinamarira T, Musuka G. Brain drain: An ever-present; significant challenge to the Zimbabwean publi health sector. Public Health Pract 2021;2:100086. https://doi.org/10.1016/j.puhip.2021.100086

2. Chingono N. Doctors sue Zimbabwe government over lack of Covid-19 protective equipment. Guardian 9 April 2020. https://www.theguardian.com/global-development/2020/apr/09/doctors-sue-zimbabwegovernment-over-lack-of-covid-19-protective-equipment (accessed 14 August 2021).

3. Kafe E. Shocking bills for COVID-19 patients. Sunday Mail, 8 August 2021. https://www.sundaymail co.zw/shocking-bills-for-covid-19-patients (accessed 25 August 2021).

Mbanje P. Is ivermectin the game changer or just another fad? NewsDay, 24 July 2021. https://www. newsday.co.zw/2021/07/is-ivermectin-the-game-changer-or-just-another-fad/ (accessed 25 August 2021).

S Afr Med J 2021;111(10):922. https://doi.org/10.7196/SAMJ.2021.v111i10.16035 